\title{
Genetic Algorithm Optimization for Multi-Biogas Mass Transfer in Hydrophobic Polymer Biocell
}

\author{
Ahmad Qasaimeh1, Talal Masoud', Hesham Al Sharie ${ }^{2}$ \\ ${ }^{1}$ Civil Engineering Department, Jadara University, Irbid, Jordan \\ ${ }^{2}$ Civil Engineering Department, Jerash University, Jerash, Jordan \\ Email: argg22@yahoo.com
}

Received 28 May 2015; accepted 1 August 2015; published 4 August 2015

Copyright (C) 2015 by authors and Scientific Research Publishing Inc.

This work is licensed under the Creative Commons Attribution International License (CC BY). http://creativecommons.org/licenses/by/4.0/

cC) (7) Open Access

\begin{abstract}
In this work, a new municipal biocell with new operation and waste management is proposed. The proposed system is biocell that is built gradually when the waste is being disposed. Different from conventional disposal at landfills, waste is put between "hydrophobic bricks" that are perforated permeable containments filled up with porous dumping material such as styrofoam. Genetic algorithm is used to optimize a transfer function that represents input of biogas percentages and output solutions for daily mass transfer rates for biogas mixture from which mass and volume of biogas within the biocell time of service are calculated. Transfer function is obtained by fitting dynamic input-output data to the input-output solutions. Input-output data are encoded to chromosomes (1, 0 digits). These chromosomes are subjected to genetic processes as crossover and mutations. Then a process of evaluation takes place. The evaluation process entails an objective function that evaluates the squared difference between experimental and calculated values. After the chromosomes are being evaluated, they are either selected for more iteration or decoded to the solutions. The decoding process is performed on optimal chromosomes to obtain optimal solutions and required optimal transfer function. Consequently, the mass and volume of biogas within the landfill time of service are determined for any ratio of $\mathrm{CH}_{4}: \mathrm{CO}_{2}$ in biocell.
\end{abstract}

\section{Keywords}

Genetic Algorithm, Biogas Transfer, Biocell, Hydrophobic Polymer

\section{Introduction}

The control of biogas, carbon dioxide and methane, in municipal landfills is an important issue due to the signi- 
ficance of these gases in terms of their pollution, hazards, and benefits.

Leachate and biogas are two emissions that are characteristic of municipal solid waste (MSW) landfills [1]. The anaerobic decomposition of landfilled MSW generates large amounts of gas that is composed of $50 \%-60 \%$ $\mathrm{CH}_{4}$ (by volume), $40 \%-50 \% \mathrm{CO}_{2}$, and other trace gases such as nitrogen and volatile organic hydrocarbons [2] [3]. Landfill gas is basically made up of methane and carbon dioxide, in addition to other small amounts of hydrogen, oxygen, nitrogen, in-organic compounds, and volatile organic compounds [4]. When released to the atmosphere, landfill biogas represents a threat to the environment, because both methane and carbon dioxide are greenhouse gases that contribute to the global warming. Methane is 21 times more powerful as greenhouse gas than carbon dioxide with a long lifespan of 150 years [5].

Landfills are estimated to account for approximately $25 \%$ of annual anthropogenic $\mathrm{CH}_{4}$ emissions in the United States [3], and as much as $20 \%$ of the global anthropogenic $\mathrm{CH}_{4}$ emissions [6]. Furthermore, methane is explosive when its volumetric concentration attains 5\% - 15\% in an air mixture. Safety and environmental concerns require that gas emissions should be controlled at landfills [7].

The landfill gas has been widely used as a fuel gas and hence landfill gas systems, especially in the western world, are developed to exploit this renewable source of energy [8]. A review in reference [9] identified 242 sites in 20 nations where landfill gas was being tapped and used as a fuel with total energy contribution exceeding of 2.037 million tonnes of coal equivalent per annum [9].

In the view of previously discussed issues, biogas control is a vital issue, and since biogas behavior in landfills is stochastic due to environmental parameters variations and there are variations of biogas mixture ratios in the emissions, the biogas flux at different ages of landfill should be controlled by intelligent method.

\section{Methodology}

In this work, a system with new operation and waste management is proposed. The proposed system is built gradually when the waste is being disposed. Different than conventional disposal methods at landfills, waste is put between "hydrophobic bricks". These bricks are containments filled up with permeable materials such as styrofoams that are water repellent and provide more space for gas transfer. To maintain the integrity of the system, cells are constructed at chronological order. Figure 1 shows the gradual construction of the biocell using permeable "bricks". To maintain the stability of the structure; each brick can be reinforced to the other bricks by key knobs that fit to keyholes [10] [11]. The design dimensions can be inspired from the scheme shown in Figure 2.

The biogas can be controlled easily in this biocell system, furthermore this handy system provides platform
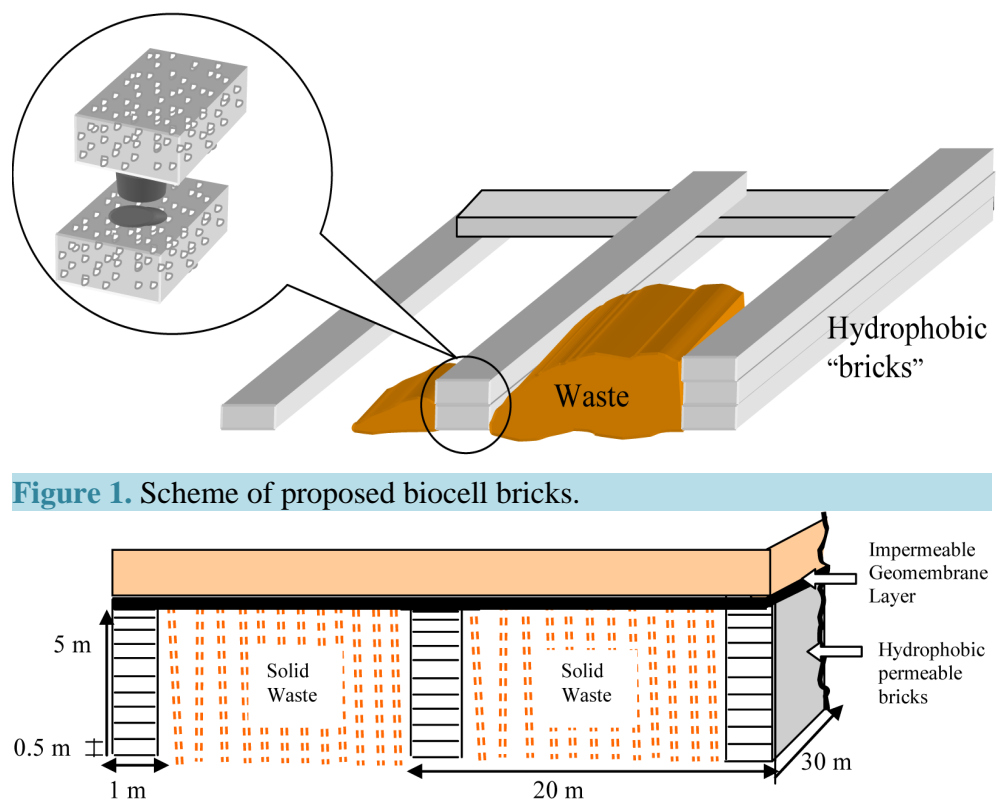

Figure 2. Biocell design configuration and dimensions. 
for intelligent and computational methods for biogas mass transfer rates and volumes estimation. Hence, genetic algorithm is herein proposed.

\section{Genetic Algorithm}

Genetic algorithms are stochastic search method introduced in the 1970s by researchers such as John Holland [12], and Ingo Rechenberg [13]. Genetic Algorithms (GA) are stochastic optimization techniques that are based on the analogy of the mechanics of biological genetics and imitate the phenomenon of selection of the fittest individuals [14]. A GA is generally characterized by:

- Coding scheme for each possible solution, using a finite string of bits (called chromosome);

- Fitness value that provides the quality of each solution;

- Initial set of solutions to the problem, called initial population, randomly generated or chosen on a prior knowledge;

- A set of reproduction, mutation and natural selection operators, that allows development of the population.

Based on simplifications of natural evolutionary processes, genetic algorithms operate on a population of solutions rather than a single solution. Each individual of a population is a potential knowledge base that is encoded before applying four operations: crossover, mutation, evaluation and natural selection, and decoding (Figure 3).

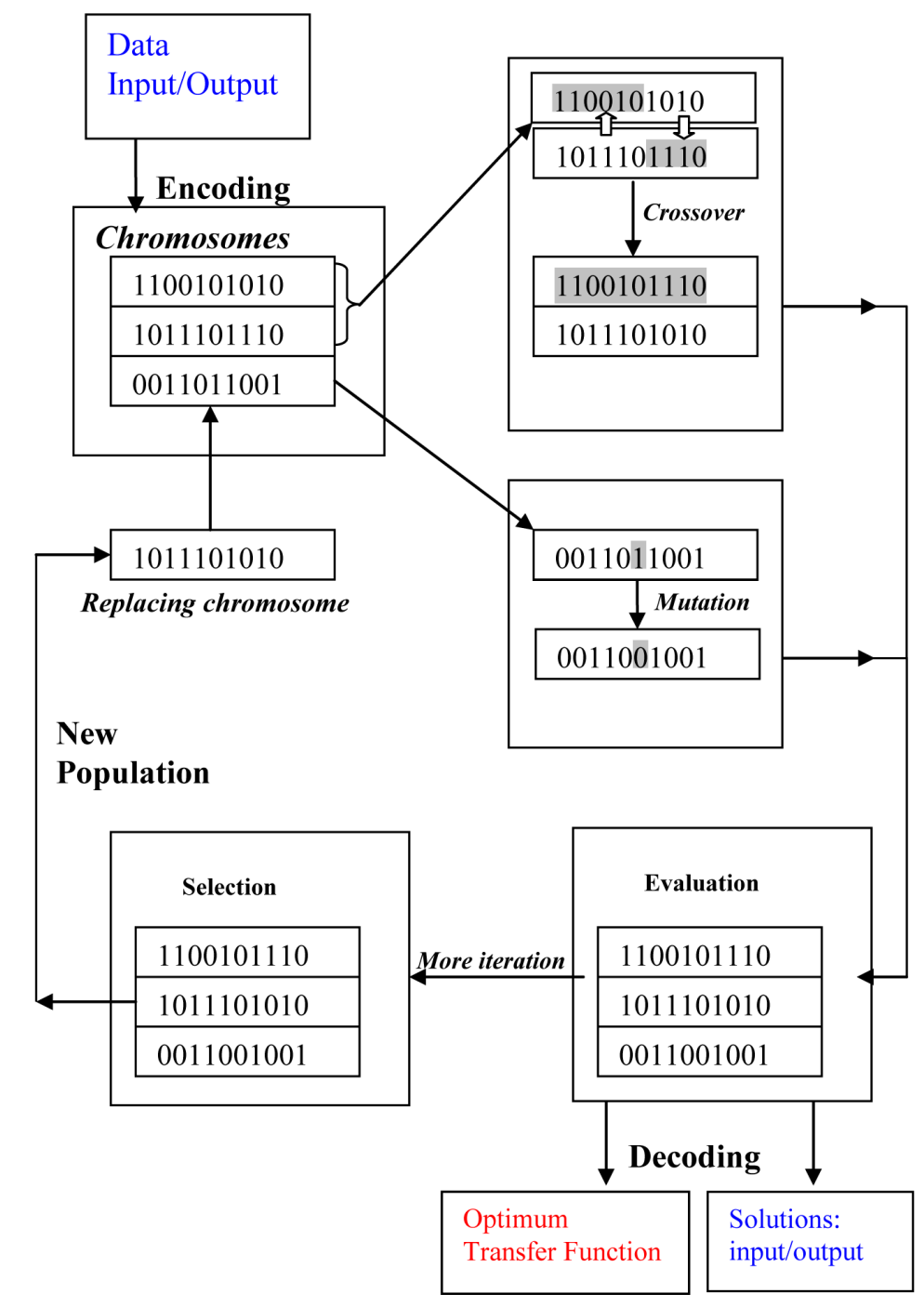

Figure 3. Genetic algorithm processes and optimization. 


\section{A. Crossover}

The progression of the population is achieved by reproduction of the best individuals based on their ability to endure natural selection. Reproduction is mainly made by crossover of the genotype (chromosome) of two parents to produce the genotype of two children [15].

\section{B. Mutation}

Mutation is a random inversion of a bit in the genotype of a new member of the population. Mutation allows trying completely different solutions.

\section{Evaluation}

The capacity of each individual to endure natural selection is evaluated by objective function. The objective function evaluates the capacity of the knowledge base to approximate the sampled data. This fitness value can be computed as the root mean square error method.

\section{Natural Selection}

Natural selection is performed on a population by keeping the most promising individuals based on their fitness. This is equivalent to using solutions that are the closest to the optimum [15].

When the genetic algorithm is in steady state, a newly child replaces the worst genotype of the population in the process of creating child solution using genetic operators such as crossover and/or mutation. This process of production is repeated until optimization criterion is met, which normally takes place when many of iterations have been accomplished. The population has often come together when the optimization criteria have been met up where the genotypes in the population are identical to each other [16]. Genetic algorithms (GA) can be applied to natural and real world problems. For instance, a fuzzy logic system used the genetic algorithms and neural networks to create fuzzy knowledge bases and rules to evaluate the capability of wetlands to remove mercury [17] [18].

In this research, the genetic algorithm is used to optimize biogas transfer rates in hydrophobic polymer medium in biocell bricks. This approach is suitable for large data with many variable parameters, and when decision cannot be ended up by human expert.

\section{GA Optimization of Biogas Transfer}

In the landfill, the important parameters (temperature, pressure, and biogas concentration) are variable. Therefore, biogas behavior is stochastic in addition to the variation of biogas ratios in the mixture of emissions, and hence GA is herein used. The investigational data in Figure 4 shows the biogas flux vs. different pressure gradients, where each curve satisfies certain biogas ratio in the emission mixture, simulating a situation on landfill, particularly at different ages of the landfill. When polymer capacity at landfill is to be designed, the amount of

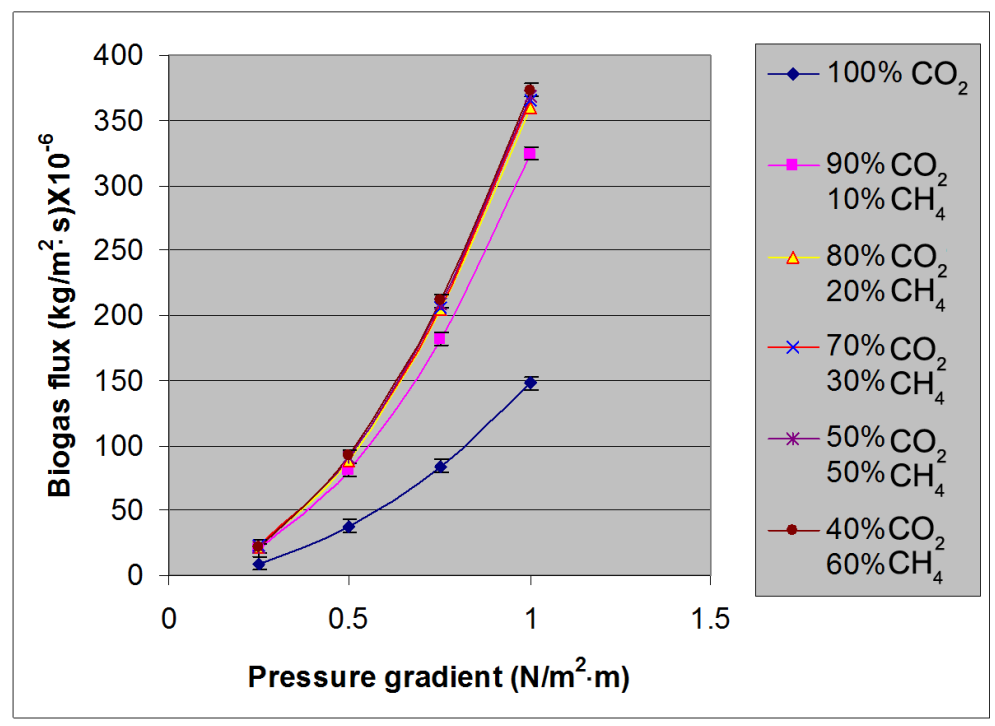

Figure 4. Biogas flux data for different percentages within different pressures (at average temperature $25^{\circ} \mathrm{C}$ ). 
gas should be taken in consideration, and hence an optimization should be conducted. Genetic algorithm has been used to optimize the design for a micro-scale unit for biogas mass transfer rate ( $\Delta F=\mathrm{d} m / \mathrm{d} t)$ in the permeable hydrophobic polymer medium (Figure 5) in constructed biocell.

Genetic algorithm is used to characterize the dynamics of input-output data by identifying a dynamic transfer function, which is a mathematical representation of the relation between the input and output used in control theory. Transfer function is obtained by fitting a dynamic input-output data to the input-output solutions. Inputoutput data are encoded to chromosomes (1, 0 digits). These chromosomes are subjected to genetic processes as crossover and mutations. Then a process of evaluation takes place. The evaluation process entails an objective function that evaluates the squared difference between experimental and calculated values. After the chromosomes are being evaluated, they are either selected for more iteration or decoded to the solutions. The selection process is performed on non-optimal chromosomes by keeping the most promising individuals based on their fitness. The decoding process is performed on optimal chromosomes to obtain optimal solutions and required optimal transfer function.

Genetic algorithm is applied by means of TransGA 1.0 (@Angel Martin 2002) [19], for optimizing the micro-scale biogas transfer rates in the porous hydrophobic medium.

The genetic algorithm proceeds in iterative processes of reproduction and mutation as shown in Figure 6 to achieve the optimized solution that is being represented by transfer function for input/output solutions. The transfer function represents the simulation of output values of biogas flux due to input values of biogas percentages during the landfill time.

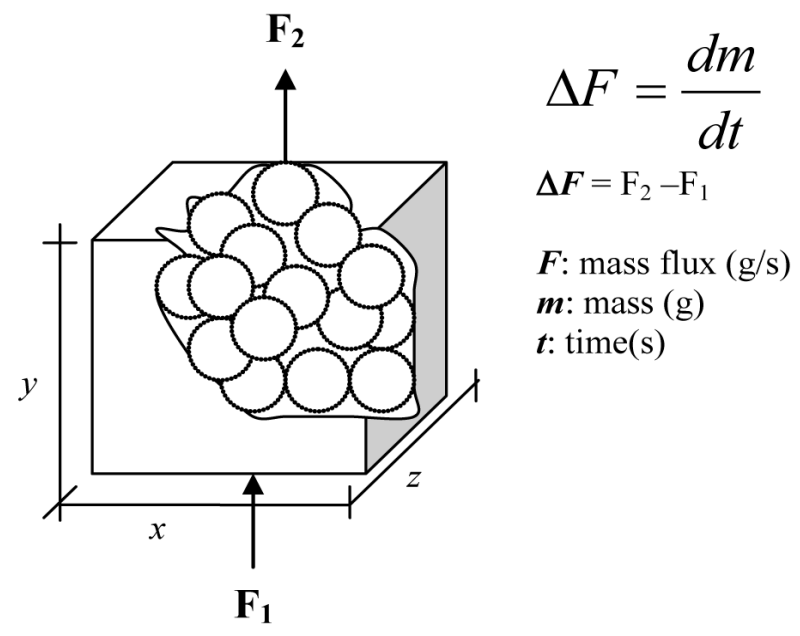

Figure 5. A micro-scale unit of porous hydrophobic polymer to be optimized by $(\mathrm{GA})$ for biogas mass transfer $(\Delta F)$.

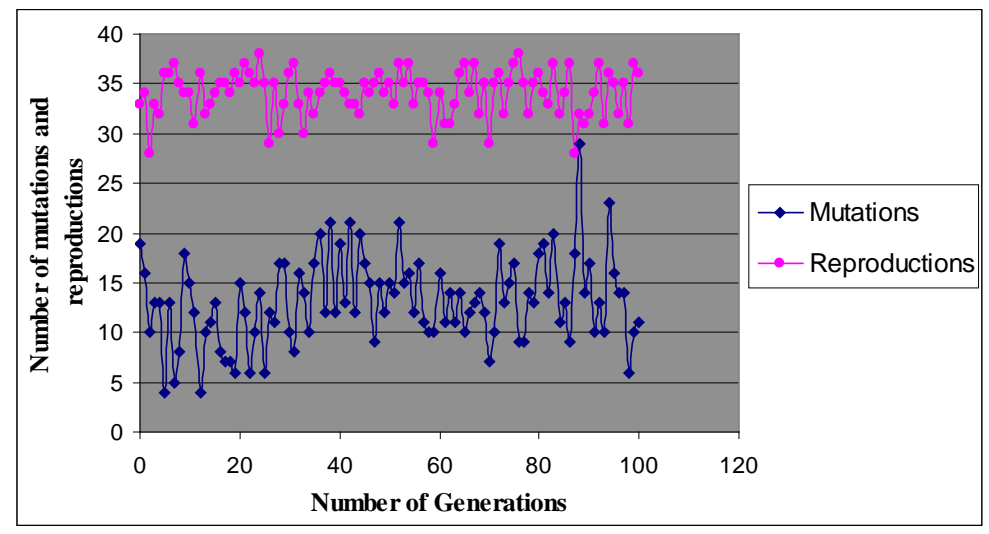

Figure 6. Mutation and reproduction processes done during GA optimization. 
The solutions were evaluated and optimized until steady state was achieved, where the genotypes in the population are very similar if not identical to each other. As shown in Figure 7, transfer functions from $F 1$ to $F 5$ represent the optimum phenotypes that are summarized as the following:

$$
\begin{gathered}
F 1=\left(z^{2}-0.242 \cdot z-0.0868\right) /\left(z^{2}-1.13 \cdot z+0.198\right) \\
F 2=\left(z^{2}-0.242 \cdot z-0.0868\right) /\left(z^{2}-1.14 \cdot z+0.206\right) \\
F 3=\left(z^{3}-0.682 \cdot z^{2}+0.0198 \cdot z+0.0382\right) /\left(z^{3}-1.9 \cdot z^{2}+1.07 \cdot z-0.155\right) \\
F 4=\left(z^{3}-0.682 \cdot z^{2}+0.0198 \cdot z+0.0382\right) /\left(z^{3}-1.88 \cdot z^{2}+1.03 \cdot z-0.141\right) \\
F 5=(z+0.888) /(z-0.704)
\end{gathered}
$$

The solution F5 in Equation (5) is the most optimal solution, because it has the least objective function value $(<0.0001)$. The objective function evaluates the capacity of the knowledge base to approximate the sampled data. This fitness value is computed as the root square mean error method. Thus the optimization process is done as minimization on the objective function is achieved. Therefore, $F 5$ is used as a representative transfer function for simulation and design of the biogas mass transfer through the porous hydrophobic polymer medium.

The transfer function which represents the biogas transfer through the permeable hydrophobic polymer is used for biocell bricks design. As shown in Figure 8, the output of the transfer function is adjusted by the coefficient $(\mathbf{K})$ to have the output $[f(u)=\mathbf{K} \times u]$ scaled up from micro-scale to the field scale. The $\mathbf{K}$ coefficient depends on the pressure gradient as it is represented by the curve in Figure 9.

The results obtained from simulation on Figure 8, represent daily biogas mass transfer rates $(\mathrm{d} m / \mathrm{d} t)$, mass, and volume. The mass transfer rate is hence shown in Figure 10 which is used to find the total daily mass and

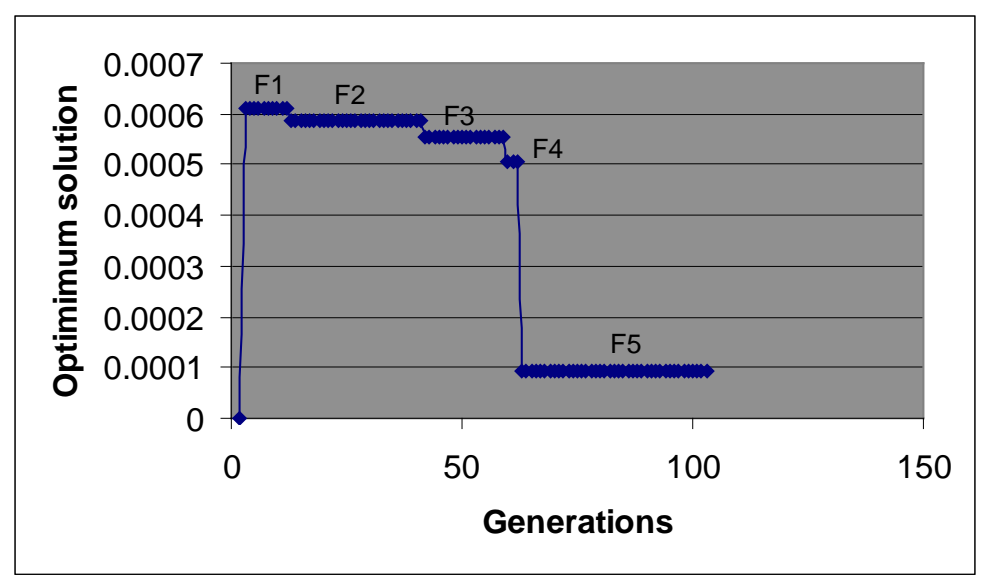

Figure 7. Optimum solutions vs. iterative generations.

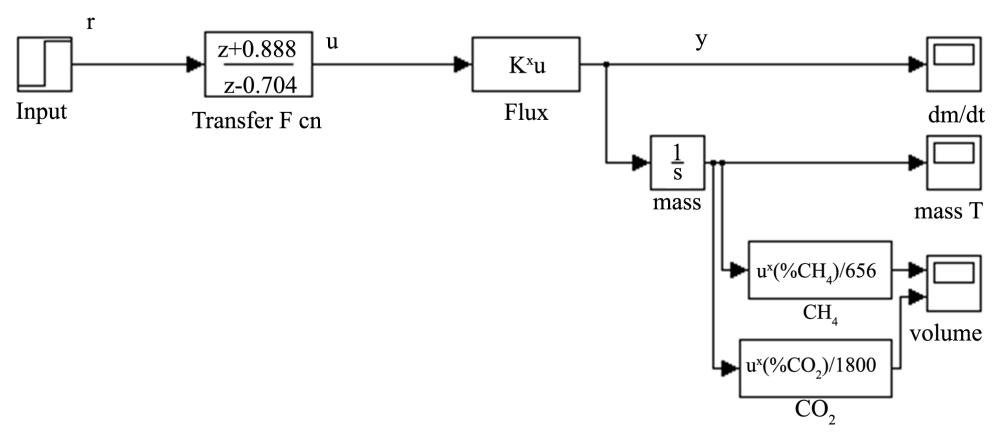

Figure 8. A simulation for daily biogas mass transfer rates, mass, and volumes using optimum transfer function. 


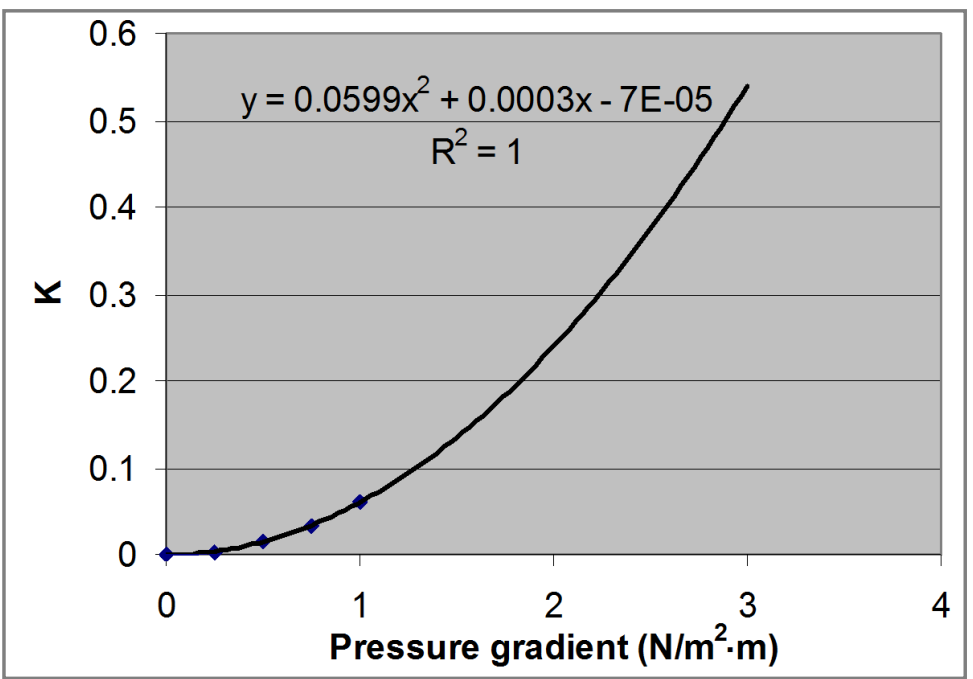

Figure 9. Simulation and forecast of scale up coefficient $(\mathrm{K})$ that adjusts the output of transfer function from micro-scale to field scale within variable pressure gradient.

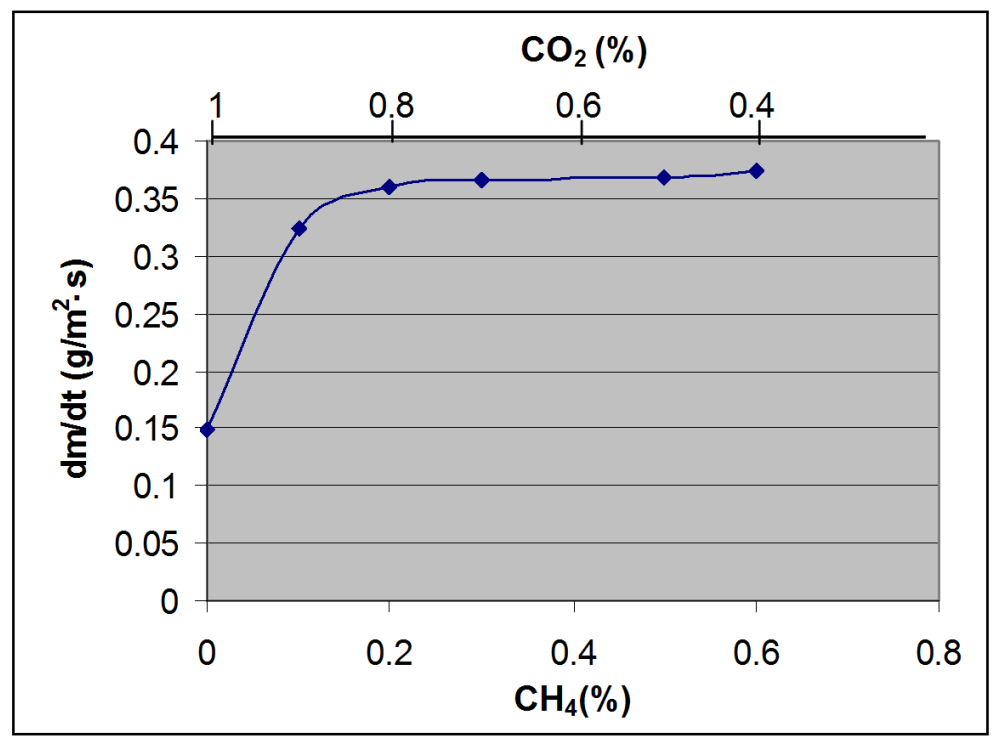

Figure 10. Biogas mass transfer rate $(\mathrm{d} m / \mathrm{d} t)$ vs. different biogas percentages at pressure gradient $1 \mathrm{~N} / \mathrm{m}^{2} \cdot \mathrm{m}$ (within 40 years and average temperature $\left.25^{\circ} \mathrm{C}\right)$.

volume of biogas as it is shown in Figure 11 and Figure 12 respectively.

Figure 13 shows design volumes and percentages for biogas mixture $\left(\mathrm{CH}_{4}, \mathrm{CO}_{2}\right)$ in biocel bricks during 40 years. The capacity and the properties of hydrophobic porous polymer used in biocell bricks should withstand the biogas mixture volumes and mass transfer rates obtained.

\section{Conclusions}

The proposed system herein is biocell that is built gradually when the waste is being disposed. Different from conventional disposal at landfill, waste is put between "hydrophobic bricks" that are permeable dumping material such as styrofoam to collect biogas.

Biogas behavior in biocells is stochastic due to variable environmental parameters. Genetic algorithm is here 


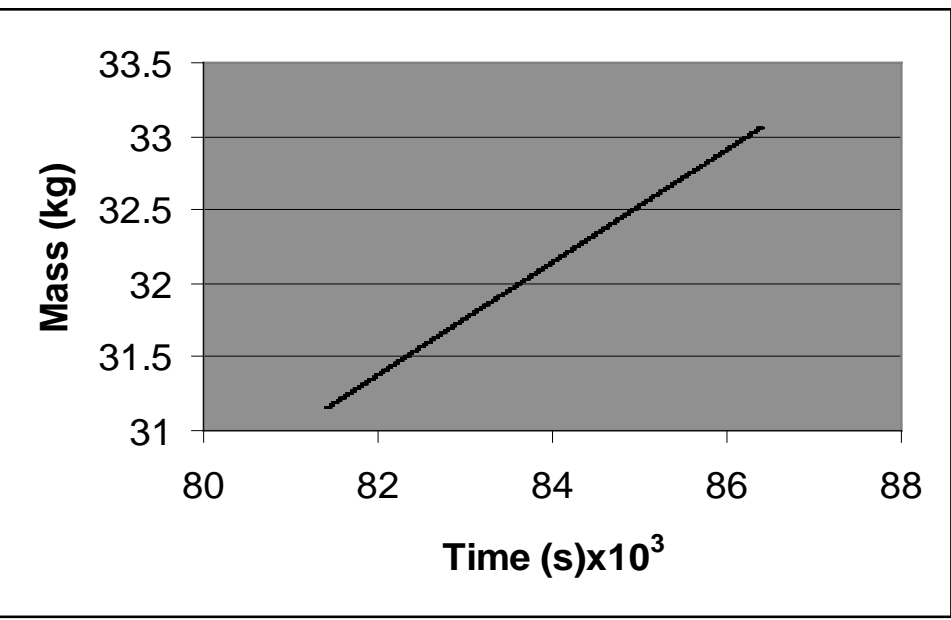

Figure 11. Total mass of biogas mixture $\left(40 \% \mathrm{CO}_{2}, 60 \% \mathrm{CH}_{4}\right)$ in landfill per day per unit area (at pressure gradient $1 \mathrm{~N} / \mathrm{m}^{2} \cdot \mathrm{m}$ and average temperature $\left.25^{\circ} \mathrm{C}\right)$.

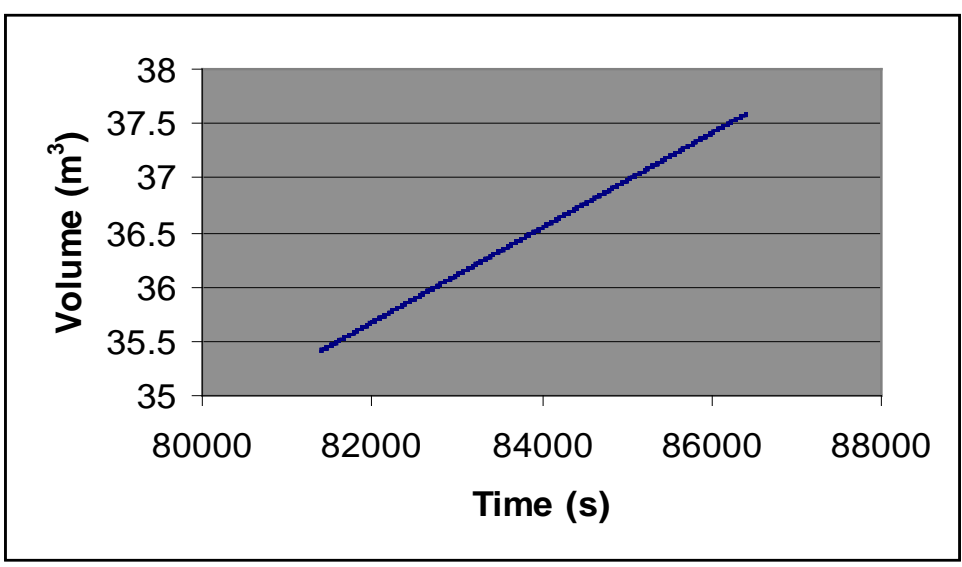

Figure 12. Total volume of biogas mixture in landfill per day per unit area (at pressure gradient $1 \mathrm{~N} / \mathrm{m}^{2} \cdot \mathrm{m}$ and average temperature $25^{\circ} \mathrm{C}$ ).

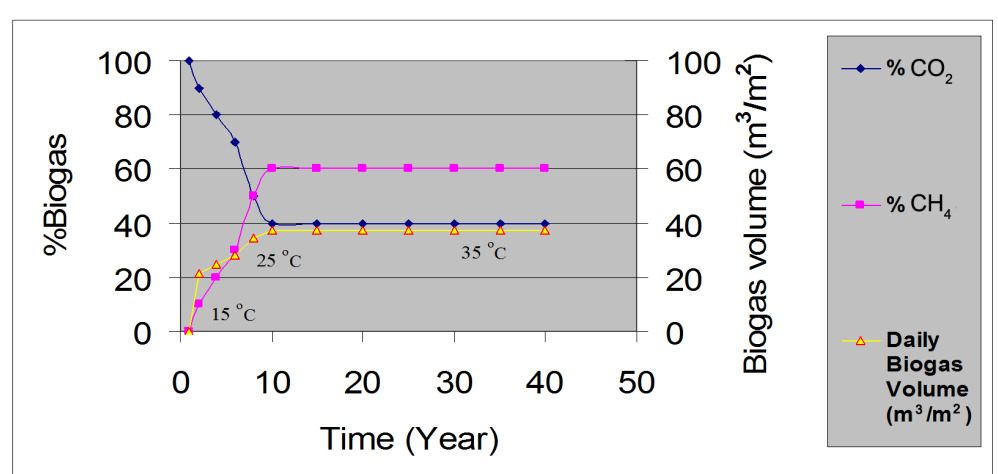

Figure 13. Biogas design volumes in the new biocell system during 40 years age.

used to optimize a transfer function that represents input of biogas percentages in biogas mixture and output solutions for daily mass transfer rates for biogas mixture from which mass and volume of biogas within the biocell time of service are calculated. 


\section{References}

[1] Manna, L., Zanetti, M. and Genon, G. (1999) Modeling Biogas Production at Landfill Site. Resources Conservation and Recycling, 26, 1-14. http://dx.doi.org/10.1016/S0921-3449(98)00049-4

[2] Kightley, D., Nedwell, D.B. and Cooper, M. (1995) Capacity for Methane Oxidation in Landfill Cover Soils Measured in Laboratory-Scale Microcosms. Applied and Environmental Microbiology, 61, 592-601.

[3] Czepiel, P.M., Mosher, B., Crill, P.M. and Harris, R.C. (1996) Quantifying the Effect of Oxidation on Landfill Methane Emissions. Journal of Geophysical Research, 101, 16721-16729. http://dx.doi.org/10.1029/96JD00222

[4] Gardner, N., Manley, B. and Pearson, J. (1993) Gas Emission from Landfills and Their Contributions to Global Warming. Applied Energy, 44, 165-174. http://dx.doi.org/10.1016/0306-2619(93)90059-X

[5] Pacey, J. (1986) Factors Influencing Landfill Gas Production. Proceeding of Joint UK/US Engineering Conference, Solihull, 28-31 October 1986, 51-59.

[6] Nozhevnikova, A., Lifshitz, A.B., Lebedev, V.S. and Zavarzin, G.A. (1993) Emission of Methane into the Atmosphere from Landfills in the Former USSR. Chemosphere, 26, 401-417. http://dx.doi.org/10.1016/0045-6535(93)90434-7

[7] Nastev, M., Therrien, Lefebvre, R. and Gélinas, P. (2001) Gas Production and Migration in Landfills and Geological Materials. Journal of Contaminant Hydrology, 52, 187-211. http://dx.doi.org/10.1016/S0169-7722(01)00158-9

[8] Shekdar, A.V. (1997) A Strategy for the Development of Landfill Gas Technology in India. Waste Management \& Research, 15, 255-266. http://dx.doi.org/10.1177/0734242X9701500304

[9] Richards, K.M. and Aitchinson, E.M. (1990) Landfill Gas: Energy and Environmental Themes. Proceedings of the International Conference on Landfill Gas: Energy and Environment 90, Bournemouth, October 1990, 21-44.

[10] Ahmad, Q., Maria, E. and Iwona, J. (2012) Investigation of Biogas Transport in Hydrophobic Permeable Medium for Biocells. Journal of Solid Waste Technology \& Management, 38, 157-168. http://dx.doi.org/10.5276/JSWTM.2012.157

[11] Qasaimeh, A.R. (2006) Intelligent Novel MSW Management System for Biogas Control in Landfill. PhD Thesis, Concordia University, Montreal.

[12] Holland, J. (1975) Adaptation in Natural and Artificial Systems. The University of Michigan Press, Ann Arbor.

[13] Rechenberg, I. (1973) Evolutionsstrategie: Optimierung technischer Systeme nach Prinzipien der biologischen evolution [Evolution Strategy: Optimization of Technical Systems According to the Principles of Biological Evolution]. Frommann-Holzboog Verlag, Stuttgart.

[14] Baron, L. (1998) Genetic Algorithm for Line Extraction. Rapport Technique EPM/RT-98/06, École Polytechnique de Montréal.

[15] Balazinski, M., Achiche, S. and Baron, L. (2000) Influences of Optimization and Selection Criteria on GeneticallyGenerated Fuzzy Knowledge Bases. (ICAMT2000) International Conference on Advanced Manufacturing Technology, Johor Bahru, Malaysia, August 2000, 159-164.

[16] Ronald, S.P. (1994) Preserving Diversity in Routing Genetic Algorithms: Comparisons with Hash Tagging. Technical Report, Department of Computer and Information Science, The University of South Australia, Australia.

[17] Qasaimeh, A., Elektorowicz, M. and Balazinski, M. (2012) GA-Fuzzy Decision Support System for Mercury Removal in Natural Waters. Computational Water, Energy, and Environmental Engineering, 1, 1-7. http://dx.doi.org/10.4236/cweee.2012.11001

[18] Qasaimeh, A., Abdallah, M. and Bani Hani, F. (2012) Adaptive Neuro-Fuzzy Logic System for Heavy Metal Sorption in Aquatic Environments. Journal of Water Resource and Protection, 4, 277-284. http://dx.doi.org/10.4236/jwarp.2012.45030

[19] Martin, A. (2002) Genetic Optimization. http://www.oocities.org/geneticoptimization 